\title{
A Five-Year Survey of Uterine Fibroids at a Nigerian Tertiary Hospital
}

\author{
A. D. Isah*, N. Adewole, E. T. Agida, K. I. Omonua \\ Department of Obstetrics and Gynaecology, University of Abuja Teaching Hospital, Abuja, Nigeria \\ Email: ${ }^{\star}$ denisanthonyisah@yahoo.com
}

How to cite this paper: Isah, A.D., Adewole, N., Agida, E.T. and Omonua, K.I. (2018) A Five-Year Survey of Uterine Fibroids at a Nigerian Tertiary Hospital. Open Journal of Obstetrics and Gynecology, 8, 468-476.

https://doi.org/10.4236/ojog.2018.85053

Received: March 25, 2018

Accepted: May 7, 2018

Published: May 10, 2018

Copyright $\odot 2018$ by authors and Scientific Research Publishing Inc. This work is licensed under the Creative Commons Attribution International License (CC BY 4.0).

http://creativecommons.org/licenses/by/4.0/
Abstract
Introduction: Uterine leiomyomas, commonly called fibroids are benign tu-
mors of uterine myometrium composing of smooth muscle with variable
amount of connective tissue and common gynecological problem among
women of reproductive age. It is the commonest tumor of the female pelvic
organ. Objective: To determine the incidence of uterine fibroids, so-
cio-demographic, clinical characteristics and outcome of uterine leiomyoma management. Material and Methods: This is a retrospective descriptive analysis of all the uterine fibroids carried out at the University of Abuja Teaching Hospital, Gwagwalada from $4^{\text {th }}$ January 2013 to $31^{\text {st }}$ December 2017. Data were obtained from medical records, gynaecological ward and theatre records of University of Abuja Teaching Hospital. Data were analyzed using socio-demographic, clinical characteristics and outcome of uterine leiomyoma management. Results were presented using simple percentages and ratios. Results: Uterine fibroids accounted for $6.4 \%$ of all gynaecological admissions and $21.3 \%$ of all major gynaecological surgeries. Uterine fibroid was found to be common between the age range $30-39$ (47.5\%) years, followed by $20-29$ (26.3\%) and 40 - 49 (15.7\%) years. One hundred and twenty-two (61.7\%) were nulliparous while $48(24.2 \%)$ were primiparous. Majority of the women 88 (44.4\%) had tertiary education, 49 (24.7\%) secondary, 48 (24.3\%) primary and $13(6.6 \%)$ had no formal education. Seventy-six (38.4\%) presented with menorrhagia, abdominal mass 71 (35.9\%), infertility 68 (34.3\%) and abdominal pain $48(24.2 \%)$. Most of the patients had multiple fibroids, 81 (40.9\%) had intramural, 70 (35.4\%) submucous and $52(26.3 \%)$ subserous. Out of 198, 165 (83.3\%) had myomectomy, 23 (11.6\%) had total abdominal hysterectomy and 9 (4.6\%) myomectomy and tuboplasty. Anaemia 41 (20.7\%) was the commonest morbidity, followed by wound infection $12(6.1 \%)$ and wound dehiscence 4 (2.0\%). No mortality was recorded during the period under review. Conclusion: Uterine fibroid is common in our environment and usually presents with menorrhagia, abdominal mass, infertility, pelvic pain, and re- 
current miscarriage. Thus healthy lifestyle should be encouraged and routine checkups conducted so as to detect and possibly treat such tumours early.

\section{Keywords}

Uterine Fibroids, Incidence, Presentation, Outcome

\section{Introduction}

Uterine leiomyomas or commonly called fibroids are benign tumors of uterine myometrium composing of smooth muscle with variable amount of connective tissue. It is the commonest tumor of the female pelvic organ [1]. These common tumors are clinically apparent in $20 \%$ of women of reproductive age and may be present in as many as $70 \%$ of uteri removed at hysterectomy [2]. However for unknown reasons, leiomyomas occurs 2 - 3 times more frequently in black than in white women. By their $5^{\text {th }}$ decade, as many as $50 \%$ of black women will have leiomyomata [3]. Although the precise cause of leiomyoma is unknown, advances have been made in the understanding of the hormonal factors, genetic factors, growth factors, and molecular biology of these benign tumours [4] [5] [6] [7]. Whether this higher prevalence among the blacks represents a genetic difference, as there is often a family history of fibroids or is perhaps associated with a higher cellular injury or inflammation resulting from an environmental agent, an infection, or hypoxia commoner in the Negroid race which has been proposed as mechanisms for initiation of leiomyoma formation [4] [8]. Uterine leiomyomas are also commoner in nulliparous and relatively infertile women [6] [7] [9] [10].

Although the presence of leiomyoma is almost never associated with death, leiomyoma may cause morbidity and affect quality of life [4] [6]. They are mostly symptomless, especially when small and even when of considerable size [5] [6] [7] [11]. Most symptomatic patients present with abdominal mass, abdominal discomfort, abnormal uterine bleeding, pressure symptoms and infertility [4] [5] [6] [7] [11].

The diagnosis of uterine leiomyoma is mainly clinical but ultrasonography is also useful. Often diagnosis of uterine leiomyoma is made incidentally at investigation for other illness [6] [7] [11].

The management of uterine leiomyoma ranges from the expectant, conservative to definite surgery. Myomectomy is the treatment of choice for young women especially those of low parity who are still desirous of children or those who want to maintain their menstrual function [6]. For older women, hysterectomy is the treatment of choice. Other conservative surgical technique for treatment of fibroid includes hysteroscopic resection of small submucoid fibroid, laser myomectomy, uterine artery embolization and bilateral uterine artery ligation [4]-[9]. 
Medical agents like Gonadotrophin Releasing hormone analogues such as buserelin and goserelin, insertion of levonorgestrel releasing intrauterine device can also be employed in patients approaching menopause or those not fit for surgery. Uterine artery embolisation is currently in use in selected cases with success. These shrink the fibroids and are used as pre-operative procedures to minimize blood loss, as primary treatment for pre-menopausal women or as palliative treatment for women who are unfit for surgery [12] [14] [15] [16].

The objective of this study is to evaluate the socio-demographic, clinical characteristics and outcome of uterine leiomyoma management in University of Abuja Teaching Hospital, Gwagwalada.

\section{Aim of the Study}

The aim of the study is therefore directed to determine the incidence of uterine fibroids in our environment, socio-demographic, clinical characteristics and outcome of uterine leiomyoma management.

\section{Materials and Methods}

The data of all patients that presented with uterine fibroids or leiomyomas between $4^{\text {th }}$ January 2013 and $31^{\text {st }}$ December 2017 was obtained from medical records, gynaecological ward and theatre records of University of Abuja Teaching Hospital. Data were analysed using socio-demographic e.g. Age, parity, educational status, marital status, clinical characteristicse. g uterine size, anatomical location, symptoms and outcome of uterine leiomyoma managemente. $g$ types of surgery and postoperative complication. The sample size was gotten from the patients that were managed with uterine fibroid in the hospital within the period study. Results were presented using simple percentages and ratios.

\section{Results}

Out of 3106 gynaecological admissions seen during the study period, 1371 were gynaecological surgeries in which 928 were major gynaecological surgeries and 198 patient case folders of uterine fibroids were analysed. Uterine fibroids accounted for $6.4 \%$ of all gynaecological admissions and $21.3 \%$ of all major gynaecological surgeries. Uterine fibroid was found to be common between the age range $30-39(47.5 \%)$ years, followed by $20-29$ (26.3\%) and $40-49$ (15.7\%) years as seen in Table 1. Nulliparous accounted for $61.7 \%$, followed by primiparous with $22.7 \%$ while by educational status, $44.4 \%$ of the women had tertiary level of education, $24.7 \%$ with secondary level, $24.3 \%$ with primary level and $6.6 \%$ with no formal education seen in Table 2 and Table 3 respectively. Marital status with educational level, $27.8 \%$ of women had tertiary level of education were unmarried while $16.7 \%$ were married, for secondary level $15.2 \%$ were unmarried and $9.6 \%$ were married, and for primary level $11.1 \%$ were unmarried while $13.6 \%$ were married (Table 4 ).

The clinical presentation of patients with uterine leiomyoma, menorhagia was 
Table 1. Age range distribution of patients with uterine leiomyoma.

\begin{tabular}{ccc}
\hline Age (years) & Number of patients & Percentage \\
\hline $20-29$ & 52 & 26.3 \\
$30-39$ & 94 & 47.5 \\
$40-49$ & 31 & 15.7 \\
$50-59$ & 1 & 0.5 \\
Total & 198 & 100 \\
\hline
\end{tabular}

Table 2. Parity distribution of patients with uterine leiomyoma.

\begin{tabular}{ccc}
\hline Parity & Number of patients & Percentage \\
0 & 122 & 61.7 \\
1 & 48 & 24.2 \\
2 & 18 & 9.1 \\
3 & 5 & 2.5 \\
4 and above & 5 & 2.5 \\
Total & 198 & 100 \\
\hline
\end{tabular}

Table 3. Educational level.

\begin{tabular}{ccc}
\hline Educational levels & Number of patients & Percentage \\
\hline Tertiary & 88 & 44.4 \\
Secondary & 49 & 24.7 \\
Primary & 48 & 24.3 \\
No formal education & 13 & 6.6 \\
Total & 198 & 100 \\
\hline
\end{tabular}

Table 4. Marital status with educational level.

\begin{tabular}{ccccc}
\hline Educational level & Unmarried & Percentage & Married & Percentage \\
\hline Tertiary & 55 & 27.8 & 33 & 16.7 \\
Secondary & 30 & 15.2 & 19 & 9.6 \\
Primary & 22 & 11.1 & 27 & 13.6 \\
No formal education & 4 & 2.0 & 9 & 4.5 \\
\hline
\end{tabular}

the commonest presentation with $38.4 \%$ followed by abdominal mass $35.9 \%$, infertility $34.3 \%$ and abdominal pain $24.2 \%$ (Table 5). Majority of the patients had uterine size within the range of 18 - 20 weeks (31.1\%), followed by 12 - 14 weeks (23.6\%) and $>20$ weeks (21.5\%), while by anatomical location of the uterine fibroids, most of the patients had multiple leiomyoma at different locations. Eighty-one (40.9\%) had intramural fibroid, 35.4\% submucous fibroid, $26.3 \%$ had subserosal fibroid, $1.5 \%$ had cervical fibroid and $7.1 \%$ were not recorded (Table 6 and Table 7). 
Table 5. Clinical presentation of patients with leiomyoma.

\begin{tabular}{ccc}
\hline Presentation & Number of patients & Percentage \\
\hline Abdominal mass & 71 & 35.9 \\
Infertility & 68 & 34.3 \\
Menorrhagia & 76 & 38.4 \\
Painful menses & 9 & 4.5 \\
Intermenstrual bleeding & 20 & 10.1 \\
Recurrent Abortion & 12 & 6.1 \\
Abdominal Pains & 48 & 24.2 \\
Vaginal discharge & 3 & 1.5 \\
\hline
\end{tabular}

Table 6. Uterine sizes at presentation.

\begin{tabular}{ccc}
\hline Uterine size (weeks) & Number of patients & Percentage \\
\hline$<12$ & 9 & 4.4 \\
$12-14$ & 47 & 23.6 \\
$15-17$ & 38 & 19.2 \\
$18-20$ & 62 & 31.3 \\
$>20$ & 43 & 21.5 \\
Total & 198 & 100 \\
\hline
\end{tabular}

Table 7. Anatomical location of uterine fibroids.

\begin{tabular}{ccc}
\hline Location of fibroids & Number of patients & Percentage \\
\hline Submucous fibroids & 70 & 35.4 \\
Subserous fibroids & 52 & 26.3 \\
Intramural fibroids & 81 & 40.9 \\
Cervical fibroids & 3 & 1.5 \\
Not Recorded & 14 & 7.1 \\
\hline
\end{tabular}

The type of surgery performed on patients, $83.3 \%$ had myomectomy, $11.6 \%$ had total abdominal hysterectomy, $4.6 \%$ had myomectomy and tuboplasty and $0.5 \%$ had vaginal polypectomy. Anaemia was the commonest complication postoperatively $(20.7 \%)$, followed by wound infection $(6.1 \%)$ and wound dehiscence (2.0\%). No mortality was recorded (Table 8 and Table 9).

Limitation: The limitation associated with this study was the fact that they were missing folders of those that had uterine fibroids within the study period. This could not be found in hospital record (Figure 1).

\section{Discussion}

Uterine leiomyoma are the most common female reproductive tract tumour, however majority of cases are asymptomatic [5] [6] [7] [8] [9] [16]. Several 
Table 8. Type of surgery performed on patients.

\begin{tabular}{ccc}
\hline Type of surgery & Number of patients & Percentage \\
\hline Myomectomy & 165 & 83.3 \\
Total Abdominal Hysterectomy & 23 & 11.6 \\
Myomectomy and Tuboplasty & 9 & 4.6 \\
Vaginal polypectomy & 1 & 0.5 \\
Total & 198 & 100 \\
\hline
\end{tabular}

Table 9. Post-operative complications.

\begin{tabular}{ccc}
\hline Type of complication & Number of patients & Percentage \\
\hline None & 141 & 71.2 \\
Anaemia & 41 & 20.7 \\
Wound infection & 12 & 6.1 \\
Wound Dehiscence & 4 & 2.0 \\
Total & 198 & 100 \\
\hline
\end{tabular}

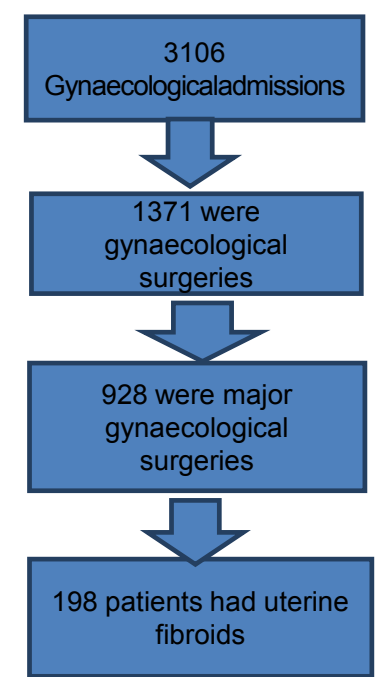

Figure 1. Flow chart.

studies have documented an increased incidence of uterine leiomyoma in black women and women of African descent [8] [10] [11]. In this study it accounted for $6.4 \%$ of all gynaecological cases over the study period. The finding is less than $7.8 \%, 8.4 \%, 9.5 \%$ and $9.8 \%$ reported from four Nigerian cities of Zaria, Ilesa, lle-lfe and Lokoja respectively [7] [9] [17]. The reason for the high incidence in this study is not far-fetched. This was because most of the women delayed marriage and pregnancy in pursuit of career as seen in Table 4. As the majority of the uterine fibroids are symptomless, the incidence remains speculative [5] [6] [7] [9] [10]. In a study that utilized ultrasound scan to screen women for leiomyoma, the prevalence ranged from $4 \%$ in women 20 to 30 years of age to $14.5 \%$ in women aged 30 to 40 years of age and $33 \%$ in women 40 to 60 years of 
age. Other studies reported that $5.4 \%$ to $77 \%$ of women have uterine leiomyomas, depending on the population studied and diagnostic method used [8] [18] [19]. In this review, however, majority 94 (47.5\%) of the cases occurred in the third and fourth decades of life; in keeping with similar reports from our environment [6] [7] [9]. The reasons for the high incidence of fibromyoma as from third decades is highly speculative, however female sex hormones have been implicated, particularly stimulation by oestrogen unbalanced by progesterone as a result of persistent anovulation [6] [7] [8] [9] [10]. Nulliparous and primiparous women accounted for 170 (85.9\%) of cases in this review in keeping with observations that leiomyoma are common in the nulliparous or relatively infertile women [5] [7] [9] [10]. Women of Negroid origin tend to develop fibroid at a younger age despite having had children [7] [9]. Compare to Caucasians, Negroid women are reported to have a 3 - 9 times increased incidence of uterine fibroid age for age. This has been attributed to genetic and racial factors [8] [10].

Most of the patients $88(44.4 \%)$ in this review had tertiary education which tallies with the observations that leiomyoma is common in the nulliparous due to chase of career or relatively infertile women [6] [7] [9] [10]. There are wide variations in the clinical presentation of uterine fibroids. They are often symptomless; however heavy menstruation (38.4\%), lower abdominal mass $(35.9 \%)$ and infertility (34.3\%) were the commonest complaint observed in this review. The incidence of abnormal uterine bleeding of $38.4 \%$ in this study is lower compared to $52.2 \%$ reported in Ilesa, Nigeria [7] [9]. The cause of the increased uterine bleeding is not always clear but have been variously been attributed to increased surface area and hyperplasia of endometrium, increased vascularity of the uterus, interstitial fibroid nodules that prevent myometrial contraction and functional ovaries often found in association with uterine fibroid [10]. The number of women in this study reporting infertility as a presenting symptom 34 . $3 \%$ is higher than $27 \%$ reported in Jamaican women [20], but similar to $37.1 \%$ reported in Lokoja, Nigeria [6]. However, it is much lower than $87.2 \%$ reported by Emembolu in Zaria Nigeria [9]. There is a well-recognized association between fibroids and infertility. The theories advanced to explain the cause of infertility in women with fibroids include; distortion of endometrial cavity, greater distance for sperm travel, and impairment of blood supply to the endometrium thereby preventing implantation, dysfunctional uterine contractility with impaired gamete transfer and enhanced androgen environment [21].

The fibroids in this report were larger than 12 weeks uterine gestation in 95.6\% of the cases and this can be attributed to the late presentation of the patients. The preponderance of multiple fibroids seen in this report is consistent with other reports. The incidence of cervical fibroids $1.5 \%$ observed in this study is lower than $4.5 \%$ and $8.7 \%$ at Lokoja and Ilesha respectively [2] [14].

In this review, all the patients had ultrasound scan done to assess the size, site and number of fibroids and to exclude other differentials like ovarian tumors, intrauterine pregnancy. Most of the patients 165 (83.3\%) in this review had myomectomy while $23(11.6 \%)$ had total abdominal hysterectomy without the 
removal of the ovaries.

Myomectomy is often done in patients with associated infertility to improve the fertility potential of when the fibroids were symptomatic with abnormal bleeding per vaginam and pain particularly in women who had not completed their family size [13]. Hysterectomy was often done in women who had symptomatic leiomyomas and had completed their family size [12] [22] [23].

Total abdominal hysterectomy is the usual operation for uterine fibroids when indicated except in a few cases where the whole uterus cannot be removed because of adhesions in which case subtotal hysterectomy could be done. Only 1 $(0.5 \%)$ had vaginal polypectomy done.

Haemorrhage remains a common complication of the surgical management of fibroids hence the high proportion of those who had blood transfusion.

In this study, the postoperative complications ranged from anaemia, wound infection and wound dehiscence and however, majority of the patients 141 (71.2\%) had no post-operative complication.

\section{Conclusion}

Uterine fibroid is common in our environment and usually presents with menorrhagia, abdominal mass, infertility, pelvic pain, and recurrent miscarriage. A lot of health problems has been attributed to or linked with fibroids in women. Some of these problems include infertility, high Body Mass Index (BMI), abnormal menstruation, etc. Of importance is the fact that younger females are now presenting with fibroids. Cessations of child bearing at an early age, high BMI, are all predisposing factors in the incidence of fibroid tumours. Thus healthy lifestyle should be encouraged and routine checkups conducted so as to detect and possibly treat such tumours early. The surgery may be complicated by post-operative anaemia from blood loss, wound infection and wound dehiscence.

\section{References}

[1] Marshall, L.M., Spiegelman, D., Barbieri, R.L., et al. (1997) Variation in the Incidence of Uterineleiomyoma among Premenopausal Women by Age and Race. Journal of Obstetrics and Gynaecology Research, 90, 967-973. https://doi.org/10.1016/S0029-7844(97)00534-6

[2] Lumsden, M.A. (2007) Uterine Leiomyomata. In: Edmonds, D.K., Ed., Dewhurst's Textbook of Obstetrics and Gynaecology, 7th Edition, Blackwell Publishing, 638-644.

[3] Drinville, J.S. and Mermarzadeh, S. (2007) Leiomyoma of the Uterus. In: Decherney, A.H., Goodwin, T.M., Nathan, L. and Laufer, N., Eds., Current Diagnosis and Treatment Obstetrics and Gynaecology, 10th Edition, McGraw Hill Companies, 639-645.

[4] Parker, W.H. (2007) Uterinemyomas: Management. Fertility and Sterility, 88, 255-271. https://doi.org/10.1016/j.fertnstert.2007.06.044

[5] Buttran, V.C.J.R. and Reiter, R.C. (1981) Uterinefibromyomata-Etiology, Symptomatology and Management. Fertility and Sterility, 4, 36-41.

[6] Anate, M. (2007) Uterine Fibroids in Federal Medical Centre, Lokoja: A Five-Year 
Review 2002-2006. The Nigerian Clinical Review Journal, 5-12.

[7] Ogunniyi, S.O. and Fasubaa, O.B. (1990) Uterine Fibromyoma in Ilesha, Nigeria. Nigerian Medical Practioner, 19, 93-95.

[8] Day Baird, D., Dunson, D.B., Hill, M.C., Cousins, D. and Schectman, J.M. (2003) High Cumulative Incidence of Uterine Leiomyoma in Black and White Women: Ultrasound Evidence. American Journal of Obstetrics and Gynaecology, 188, 100-107. https://doi.org/10.1067/mob.2003.99

[9] Emembolu, J.O. (1987) Uterinefibromyomata; Presentation and Management in Northern Nigeria. International Journal of Gynecology and Obstetrics, 25, 413-416. https://doi.org/10.1016/0020-7292(87)90349-3

[10] Vollenhoven, B.J., Lawerence, A.S. and Healy, D.L. (1990) Uterine Fibroids: A Clinical Review. British Journal of Obstetrics and Gynaecology, 97, 285-298. https://doi.org/10.1111/j.1471-0528.1990.tb01804.x

[11] Briggs, N.D. (1995) Common Gynaecological Tumours. Tropical Journal of Obstetrics and Gynaecology, 12, 62-71.

[12] Low, D.G. (1990) Benign Tumors of the Uterus. In: Edmunds, D.K., Ed., Dewhurst's Textbook of Obstetrics and Gynaecology for Postgraduates, 6th Edition, Blackwell Science Ltd., Hoboken, 552-559.

[13] Wallach, E.E. (1992) Myomectomy In: Thompson, J.D. and Rock, J.B., Eds., Telinde's Operative Gynaecology, 7th Edition, Lippincott Company, New York, 647-662.

[14] ACOG Technical Bulletin (1994) Uterine Leiomyomata. International Journal of Gynecology \& Obstetrics, 46, 73-82.

[15] Tindall, V.R. (1987) Tumors of the Corpus Uteri In: Jeffocoate's Principles of Gynaecology, 5th Edition, Butterworths, London, 417-442.

[16] Walker, C.L. and Stewart, E.A. (2005) Uterine Fibroids: The Elephant in the Room. Science, 308, 1589-1592. https://doi.org/10.1126/science.1112063

[17] Okogbo, F.O., Ezechi, O.C., Loto, O.M. and Ezeobi, P.M. (2011) Uterine Leiomyomata in South Western Nigeria: A Clinical Study of Presentations and Management Outcome. African Health Sciences, 11, 271-278.

[18] Lurie, S., Piper, I., Woliovitch, I. and Glezerman, M. (2005) Age-Related Prevalence of Sonographically Confirmed Uterine Myomas. Journal of Obstetrics and Gynaecology, 25, 42-44. https://doi.org/10.1080/01443610400024583

[19] Lethaby, A. and Vollenhoven, B. (2005) Fibroids (Uterine Myomatosis, Leiomyomas). American Family Physician, 71, 1753-1756.

[20] Jonas, H.S. and Masterdon, B.J. (1972) Giant Uterine Tumours: Case Report and Review of Literature. Obstetrics and Gynecology, 50, 25-29.

[21] Kwawukume, E.Y. (2017) Leiomyoma of the Uterus, In: Kwawukume, E.Y. and Ntumy, M., Eds., Comprehensive Gynaecology in the Tropics, 2nd Edition, Graphic Packaging Limited, Accra, 173-186.

[22] Omu, A.E., Ihejerika, I.J. and Tabowie, G. (1984) Management of Uterine Fibroids at the University of Benin Teaching Hospital. Tropical Doctor, 14, 82-85. https://doi.org/10.1177/004947558401400213

[23] Whitefield, C.R. (1995) Benign Tumors of the Uterus In: Dewhurst's Textbook of Obstetrics and Gynaecology for Postgraduates, 5th Edition, Blackwell Scientific Publications, Hoboken, 225-247. 